\title{
Nanoparticulate materials and regulatory policy in Europe An analysis of stakeholder perspectives
}

\section{Journal Article}

Author(s):

Helland, Åsgeir; Kastenholz, Hans; Thidell, Aake; Arnfalk, Peter; Deppert, Knut

Publication date:

2006-10

Permanent link:

https://doi.org/10.3929/ethz-b-000035690

Rights / license:

In Copyright - Non-Commercial Use Permitted

Originally published in:

Journal of Nanoparticle Research 8(5), https://doi.org/10.1007/s11051-006-9096-3 


\title{
Nanoparticulate materials and regulatory policy in Europe: An analysis of stakeholder perspectives
}

\author{
Aasgeir Helland ${ }^{1,2, *}$, Hans Kastenholz ${ }^{1}$, Aake Thidell ${ }^{3}$, Peter Arnfalk ${ }^{3}$ and Knut Deppert ${ }^{4}$ \\ ${ }^{1}$ Technology and Society Lab, EMPA Materials Science \& Technology, Lerchenfeldstrasse 5, 9014, St. \\ Gallen, Switzerland; ${ }^{2}$ Institute for Human-Environment Systems, ETH Zurich, 8092 Zurich, Switzerland; \\ ${ }^{3}$ International Institute for Industrial Environmental Economics, Lund University, Box 196, S-22100, Lund, \\ Sweden; ${ }^{4}$ Solid State Physics/Nanometer Structure Consortium, Lund University, Box 118, S-22100, Lund, \\ Sweden; *Author for correspondence (Tel.: +41-71-2747848; Fax: +41-71-2747862; E-mail: asgeir.hel- \\ land@empa.ch)
}

Received 14 November 2005; accepted in revised form 20 March 2006

Key words: engineered nanomaterials, environmental health, human health, nanoparticulate materials, regulatory policy, nanotechnology, societal implications

\begin{abstract}
The novel properties of nanoparticulate materials (NPM) and the rapid development of NPM based products have raised many unanswered questions and concerns by different stakeholders over its consequences for the environment and human health. These concerns have led to an increasing discussion in both the US and Europe about possible regulatory policies for NPM. In this article a comparative study of stakeholders' perceptions on regulatory policy issues with NPM in Europe is presented. It was found that industry wants to regulate this area if the scientific evidence demonstrates that NPM are harmful, but also that the regulatory bodies do not find it necessary at this point of time to regulate until scientific evidence demonstrates that NPM are harmful. This research therefore shows that there will most likely not be any regulatory interventions until there is an established and convincing scientific knowledge base demonstrating that NPM can be hazardous. It is furthermore discussed in this article the different roles and responsibilities of the stakeholders in financing the research required to establish the necessary level of fundamental scientific evidence. It was also found that the activity of the regulatory bodies on this issue differ between the European countries.
\end{abstract}

\section{Introduction}

The novel properties of nanoparticulate materials (NPM) are researched widely for many different applications ranging from light-weight materials, drug-delivery systems to renewable energy. Expectations are huge: nanotechnology is believed to change the way everything is made and designed in society (NSTC, 1999). However, the novel properties of NPM and the rapid development of NPM based products have also raised many unanswered questions and concerns over its consequences for the environment and human health. In short: do we have reasons to worry about NPM?

Nanoparticles are often defined as particles less than $100 \mathrm{~nm}$ in diameter (The Royal Society \& The Royal Academy of Engineering, 2004) and can be divided into three main categories (Helland, 2004): (i) particles that are produced unintentionally (e.g., diesel engines and welding processes) or originate from natural sources (volcanoes and 
forest fire); (ii) particles produced in bulk in traditional industries such as the chemical industry or the polymer industry (e.g., carbon black and titanium dioxide); (iii) particles that are deliberately engineered to have specific properties and characteristics only existing in the nano-range and utilized for a specific function (e.g., carbon nanotubes, fullerenes and quantum dots); In this article, the term ,nanoparticulate materials' represents the two latter categories as engineered materials that are less than $100 \mathrm{~nm}$ in at least two dimensions.

The scientific literature available of potential hazards of NPM indicates that NPM may be harmful, although the scientific knowledge base is minimal in these areas (Warheit, 2004). The exposure to ambient air particles and their influence on health is well documented through epidemiological studies. These epidemiological studies suggest that an increase in ambient particle concentration is related to an increase in acute morbidity and mortality (von Klot et al., 2005). Studies indicate that the decrease of particle size and the corresponding increase in relative surface area correlates with an increase in defense reaction in the lung tissue (Oberdorster, 2001; Donaldson, et al., 2002; Zhang et al., 2003; Donaldson et al., 2004a) and the inhalation of nanoparticles may cause diseases like lung cancer, fibrosis and inflammation in the lung and further worsen cardiovascular or respiratory diseases like asthma or bronchitis (Borm, 2004; Donaldson, 2004b; Stone, 2004). However, it is important to note that this lung toxicity database has been limited to studies of three types of nanoparticles: titanium dioxide, carbon black and diesel particles (Warheit, 2004). NPM may also translocate within the body, for example from the nose and lungs to the central nerve system, the brain, into the systemic circulation and to organs like the liver (Nemmar et al., 2001; Takenaka et al., 2001; Kreyling et al., 2002; Oberdorster et al., 2002; 2004; Takenaka et al., 2004). The research covering the new types of NPM is limited and the number of studies of the environmental impacts of NPM are few. Carbon nanotubes have been shown to cause granulomas in the lungs of animals, an immunological response to foreign objects (Lam et al., 2004; Warheit et al., 2004; Muller et al., 2005; Shvedova et al., 2005), and was found in one study to be more toxic than carbon black and quartz (Lam et al., 2004). Fullerenes have been shown in studies to be bioavailable when released in aqueous environments, cause lipid peroxidation in fishbrain (Oberdorster, 2004a) and inhibit bacterial growth (Fortner et al., 2005). Rendering the surface chemistry or coating may provide an attractive strategy in reducing toxicity. A recent study has shown that increasing the degree of sidewall functionalization decreases the cytotoxicity of single-walled carbon nanotubes (Sayes et al., 2006). However, this may be difficult in some environmental settings or the body. For example, UV-light or enzymes may modify the safety coatings by turning coated fullerenes into more toxic uncoated fullerenes (E. Oberdorster, 2004b). Two other factors that determine the potential impacts of NPM on environmental and human health are the level of biopersistency and biodegradability (Borm \& Kreyling, 2004). The concerns regarding the toxic potential of NPM have lead to the announcement of a new sub-discipline called nanotoxicology, which has been defined as safety evaluation of engineered nanostructures and nanodevices (Oberdörster et al., 2005).

Based on the concerns raised and the limited regulations for producers on how to deal with their products, there is an increasing debate in the US and Europe on regulatory issues, NPM handling procedures and labeling of nanobased products (Haum et al., 2004; Roco, 2005). For example, the reinsurance company Swiss Re sees one of the biggest challenge for regulations is to develop standardizations of nanomaterials and substances and a universal nomenclature (Hett, 2004). A report from the Royal Society in the UK finds it likely that several regulatory bodies will have to look deeper into the issue and express that they

'strongly believe that flexible and proportionate regulatory measures informed by scientific evidence are beneficial to everybody; the public, consumers and employees are protected from harm while industry is able to participate in developing standards and preparing guidance to ensure a level playing field and reduced risk of liability.'

(The Royal Society \& The Royal Academy of Engineering, 2004).

The European Commission (EC) action plan for 2005-2009 states that because the presence of 
nanobased products in the market is expected to increase rapidly, particular attention should be paid to market ready products and risk assessments should be done ex ante commercialization due to the potential impacts of nanoparticles on human health and the environment (EC, 2005a). The EC states further in the action plan that it will examine and, if needed, propose adaptations of European Union regulations, develop risk assessments for nanoproducts integrating all stages of the life cycle of the technology, promote measures for minimizing exposure of workers, consumers and the environment, and identify and address safety concerns with applications and use of nanoscience and nanotechnology at the earliest possible stage.

Limited research efforts have been focused on the perceptions of the different stakeholders of NPM regulations. However, Haum et al. (2004) offered a preliminary finding from their survey. Nanotechnology is only in rare cases a part of the regulatory body's agenda and argued that their findings demonstrated that, the regulators in different member states in the European Region have taken no action at all'. How the different actors perceive the issue is important for establishing a successful scheme that supports the beneficial innovations, but at the same time protects human health and environment. Therefore, the purpose of this research was to investigate stakeholders' perceptions of NPM regulations, with a closer focus on occupational health settings since exposure to humans in occupational settings will take place first and thus potential effects are expected there first.

This study is a comparative assessment of the perceptions of different stakeholders on regulatory policy issues in Europe.

\section{Methodology}

The information in this study was collected through structured phone interviews with experts from academia, an outspoken non-governmental organisation (NGO), representatives from occupational health and safety agencies, a representative from the EC and NPM producer representatives with expertise in occupational health and safety and environmental issues. There were in total 21 interviews conducted.
We found it necessary to have an interdiciplinary pool of experts from academia. As such we composed a list of 20 scientists with expertise of NPM regarding environmental impacts such as ecotoxicology, and health impacts such as occupational health, cell toxicity, lung toxicity and biological aspects. They were located from a literature review as key authors, participation lists of conferences and workshops in the field and suggestions from other people working in the field. They are considered as leading scientists in Europe and the USA. From this pool in-depth, structured interviews were conducted by phone with nine scientists from Europe and, as we found few European scientists with expertise in environmental issues, we also interviewed one scientist from the USA.

There are a limited number of NGOs active in the nanotechnology debate in Europe. The two media-dominant NGOs, with a position on nanotechnology, Greenpeace in the UK and the ETC-group's European representative, were asked to participate, but only the ETC-group chose to. The interview method and questions were the same as for the scientists.

The representatives from the occupational health and safety agencies in Germany, Switzerland and the UK and the representative from the EC were chosen by the organizations themselves in response to a direct request to their main offices for an interview about risks of NPM. The opinions, conclusions and recommendations expressed were those of the representatives and do not necessarily represent the opinion of their organizations. The interviews were conducted by phone and consisted of structured questions that were more detailed on occupational health regulatory issues than for scientists and NGO.

The NPM producers were interviewed by phone and/or through written surveys with the same questions for both interviewing methods, which were more detailed on industrial regulatory issues. The companies were selected based on literature reviews of NPM producers, participation-lists in workshops and conferences and from suggestions of experts and others working in the field of NPM research and development. From these different sources, the most prominent producers in terms of research or quantity of NPM produced were asked to participate. There were in total 13 producers that were approached and six of those chose to 
participate. The companies wished to be anonymous and are thus not identified here. In general, there were two categories of companies participating, large multinational chemical companies, hereby called 'established companies', and relatively recently founded companies, hereby named ,young companies'. The established companies have several products in their portfolio and more resources than the young companies. The NPM produced by the established companies can typically be produced in several tons per year and include for example established NPM such as carbon black. The young companies have typically developed new NPM as for example carbon nanotubes. The production methods typically originate from a university research lab and the production volume is still small. There are three companies representing each category.

To uncover the perceptions of these stakeholders, in-depth structured interviews were conducted. The interviews were then transcribed and the stakeholders were given the opportunity to clarify their statements based on the transcript. The answers were then analyzed with the perceptions of the following regulatory issues as common nominators: need of regulations, point of time, type of regulations and which NPM should be regulated. The different stakeholders were then compared and the implications discussed.

\section{Stakeholder perceptions of NPM regulatory policy}

Identifying the perceptions of stakeholders is important for understanding the stakeholders' potential impact on projects and processes. In turn, this contributes to the formulation of appropriate strategies that maximizes a stakeholder's positive influence and minimizes any negative influence (Bourne \& Walker, 2005). The development of NPM, as any emerging technology, is characterized with high uncertainty and ambiguity. The important stakeholders in the NPM sphere, such as scientists, NGOs, and industry, will strongly influence the debate on regulatory policy issues and thus, how regulatory schemes will function and be implemented. Whether a regulatory scheme for NPM is needed or how successfully it can be implemented will be largely influenced by these stakeholders as well as the regulatory bodies themselves. In a UK survey studying the general public's awareness of nanotechnology, only $19 \%$ of the survey sample could offer any form of definition of nanotechnology (The Royal Society \& The Royal Academy of Engineering, 2004). Due to this low public awareness, we did not include the public or the labor as stakeholders for our study. We therefore investigated the perceptions of the following stakeholders scientists, NGOs, regulatory bodies and industry in order to see where there are consensus points, as well as opposing opinions. The following sections summarize the stakeholder opinions as given in the interviews.

\section{Scientists about regulations}

Today materials are generally regulated by unit of mass, but this approach is problematic for NPM, as it does not take their specific properties into account. Therefore, it is important to find out which measurement unit(s) regulations should address including the unique properties of NPM.

The authorities should initiate exposure assessment and proper toxicological research to find out how severe these risks may be. However in the field of air pollution, there are already enough rationale, based on scientific evidence, to regulate NPM originating from the combustion process. The exposure assessments and toxicological research initiated by the authorities should be complemented by implementing toxicology and screening tests for producers, to ensure that producers do proper risk assessments before launching the products. If authorities are working together with industry and the scientific community, precautionary measures can be taken which are based on epidemiological and toxicological studies. However, history has shown that it takes too long between when scientists say there might be a problem and until something actually happens from the authorities' side. Therefore, authorities could bypass the normal way of asking for scientific evidence and immediately start thinking about what may need to be done in order to have predictable ways of dealing with the problem if it turns out to be necessary. This might involve organizing the regulatory process differently, such as calling for workshops early in the process. Informing the producers about risks associated with their products could be another task of the authorities and at this stage issuing precautionary 
guidelines instead of regulations could be an important tool of prevention.

\section{NGO about regulations}

The ETC-group finds that NPM need to be individually treated in regulatory settings and believes that an approach similar to the new EU chemical regulation, $\mathrm{REACH}^{1}$ (EC, 2003), could be appropriate for NPM. With this type of regulation, producers have to prove their products safe through providing a risk assessment to sell their products on the European market. However, before that can happen, a standardised model on how to do toxicological tests methods for NPM needs to be agreed to by scientists. These tests should be done by independent assessment bodies. Furthermore, the ETC-group wants agreed protocols on how NPM is handled in laboratories or production sites. In turn, this might make ETCgroup's current call for a moratorium obsolete.

\section{European Commission about regulations}

There is today no exposure data available in the European Union. What exists are hazards identified for NPM derived through lab experiments or theoretical considerations. In response to the raised considerations, the EC has convened expert groups and are performing workshops to discuss the issue. Additionally in the 'Towards a European Strategy for Nanotechnology' communication, which is a non-binding policy declaration, there are also actions identified (EC, 2004). In the light of history, the representative believes it is quite unique that the EC is considering risks from the start of an ECpromotion of a technology. The representative also believes that the EC as an institution cannot move much faster than it has done.

Criticism has been raised against the National Nanotechnology Initiative in the US, questioning that some of the environmental budget is being

\footnotetext{
${ }^{1}$ It is expected that the final decision on REACH will be reached by the European Parliament and Council in autumn 2006 and that the operational requirements will be applied from 2008 onwards. The new chemical legislation will ,...reverse the burden of proof so that industry, both producers and importers of substances, rather than the public authorities, will have to assume greater responsibility for providing the necessary information and taking effective risk management measures.' (EC, 2005b).
}

used to research remediation solutions of existing problems, without seriously researching whether the technology itself has environmental impacts (Service, 2004). The representative admits that also within the EU applications for fixing existing problems may be promoted, even though testing whether they are inherently safe for the environment or human health has not occurred. However, through the declarations and statements that the EC has made, the representative believes that the EC sees the need to do nano-toxicological and ecotoxicological research and for redoing the toxicology that is done for bulk substances for nanoparticulate substances.

At this stage in the development, EC is cautious, but not pre-cautious in the sense of invoking the precautionary principle as declared in the communication from the commission on the precautionary principle (EC, 2000). However, the EC is precautious in the way that it tries to finance research projects that include elements of risk awareness and risk analysis and the EC communications on nanotechnology have a strong component of safety, and it seems likely that it will be followed up by the action plan. The health and safety policies are national competences and the EC should not trespass the limits of EC competences and thus will leave it to the member states to handle those issues. However, the EC tries to inform and raise awareness on this issue among the member states as well as industry.

The EC is not ahead of the market. There is an existing situation with market available products and the EC needs to have a position on how to address these products. The EC does not have a position on how to regulate/deal with the variety of different NPM which is a big challenge, but in any case it seems to be too early on having a position on a possible REACH (EC, 2003) approach for NPM. The existing regulations also need to be examined and it needs to be determined whether another type of legislation should address nanoparticulate substances than those for bulk substances.

\section{Producers about regulations in occupational settings}

The companies interviewed in this section can be divided into the two categories young and established companies, as described in the methodology section. 
The young companies believe that for occupational settings, NPM are covered under current regulations although the exposure levels might need to be set differently for NPM than other materials. These regulations should be specified for the individual material and its form, but today and at this stage in the development, it would be premature to introduce specific regulations especially since the risks need to be scientifically demonstrated. However, doing toxicology tests for each individual material would be too expensive for the industry. Issuing regulations demanding such testing would fail as it would break the economy of the industry. Therefore, regulators might consider issuing guidelines rather than strict regulations and disseminate information on toxicity to the industry. At this stage in the development, the commitment to the industry's Responsible Care $^{2}$ program would be enough.

The established companies treat NPM as chemically fine powder, therefore they see existing chemical regulations as sufficient for these materials, but they may need to be more clearly specified for this size range. Therefore, it is necessary to discover specific knowledge of the toxicity of the material and establish exposure limits based on the right unit of measurement. Then, existing regulations could be amended to regulate all areas from laboratory and personal equipment against concerns of work time and maximum work area concentrations. It does not seem to be necessary to establish new regulations for the implemented occupation hygiene systems, but most of all, the threshold levels have to be investigated, personal monitoring methods are needed to improve safety and materials handling at workplaces, and the existing safety measures have to be adapted to possible additional hazardous properties of the NPM (Table 1).

\section{Occupation Health Authorities about regulations in occupational settings}

All responding health authorities agreed there are large uncertainties regarding the health risks and hazards of NPM and knowledge gaps on the

\footnotetext{
${ }^{2}$ Responsible Care - A voluntary program to achieve improvements in environmental, health and safety performance beyond levels required by the government (ICCA, 2005).
}

exposure level as well as dose-response questions. In addition, small particles are problematic especially considering the analogies of dust, asbestos and fibers, so more studies need to be done to fill the present data gaps, focusing on the kinetics, inhalation, dermal exposure route, the body burden that can be reached through the exposure routes and the effects on other organs. Today, for example, it is only known that there will be an effect in the lungs, but the mechanisms needs to be elaborated. The occupational regulatory body in Germany is of the opinion that they must wait until it is known which substances will be used in the nanotechnologies and then assess these substances for risks. In the UK the risks from inhalation and dermal exposure to NPM are seen as the same as would be considered for any new chemical. One problem is that it is not possible to determine which controls may be adequate before toxicology is better understood. Currently, this is to be done on a case-by-case basis. Some of the new NPM are made to exhibit novel properties that might be an issue for toxicity and could have a different toxicity value than with conventional materials. This could for example be due to different dose kinetics as smaller particles dissolve quicker or deposit differently in the lungs than larger particles. It could also be that the NPM have the same toxicity as bulk materials, but that the way the NPM impacts the body is different.

The severity of the risks of NPM is difficult to estimate as there are no epidemiological studies on exposed humans and no exposure information. The severity depends largely on how and where the material is used. Occupational health authorities state that they have to look at the containment of the product and in which form it occurs, as NPM in bulk powder form are likely to be more problematic than in liquid suspension. The occupational risk today might be quite low unless the material has a toxicity which is extremely high and containment is hard to achieve. The range of different NPM is significant, consequently it is difficult to differentiate and rank what the concerns might be for the different types of NPM. However, it is assumed that the smaller the particles are, the greater are the hazards. It is reasonable to be most concerned about getting data on the new novel particles and fibers and especially those with a novel catalytic function or a novel binding function. Therefore, it is recommended to restrict 
Table 1. Summary of industry perception on regulations of occupational settings

\begin{tabular}{lc}
\hline Young Companies & Established Companies \\
\hline Risks need to be scientifically demonstrated. & $\begin{array}{c}\text { Existing regulations on fine powder amended } \\
\text { for NPM. } \\
\text { Individual knowledge on substances needs } \\
\text { to be gained first. } \\
\text { Exposure levels should be established. }\end{array}$ \\
$\begin{array}{l}\text { Regulations should be specified for the individual material } \\
\text { and its form. }\end{array}$ & \\
$\begin{array}{l}\text { Exposure levels might need to be amended. } \\
\text { Too expensive to do toxicological tests on each material } \\
\text { for industry. }\end{array}$ & \\
$\begin{array}{l}\text { Guidelines may be better than regulations. } \\
\text { Authorities should disseminate information. } \\
\text { In the current stage of development, the voluntary } \\
\text { industry commitment to Responsible Care is sufficient. }\end{array}$ & \\
\hline
\end{tabular}

exposure as much as technically possible as a precautionary measure.

At the moment there is not enough known to regulate the occupational settings and there is no plan to regulate this area. In Switzerland they will wait and see what is going on in this area and if it is necessary, measures will be taken in cooperation with producers. It is necessary to develop measurement methods and limit values in air first. If the normal technical measures do not work for NPM, special standards would be prescribed. In Germany they foresee limit values to guide industry and thereafter provide a specific standard. In the UK they do not pereceive nanotechnology as one subject, because it is many different technologies, products and processes. In the UK, they do not believe a special set of regulations will be needed to cover nanotechnology, but rather an amendment of existing ones as, for example, including nano-fibers in the definition of fibers. The risks of nanotechnology will probably be covered in the day-to-day industrial routine in the future, such as the risk of e.g., electric shocks is covered today (Table 2).

\section{Discussion}

\section{Comparing the stakeholder perceptions}

The regulatory bodies and industry seem to be aware that there might be potential risks of NPM and concur it is not possible today to perform a traditional risk assessment based on the current knowledge level. They support that more research should be done on different types of NPM and that these materials need to be assessed on a case by case basis. Not only the EC but also the occupational authorities seem to give this area a low priority as they have not seen any scientific research that shows reasons for great concern. However, if evidence demonstrates rationales for concerns, the authorities will try to regulate the area. However, at the moment there exists no plan on how to do it. The authorities and industry seem to foresee amending existing regulations as more likely than creating new ones.

Whereas the occupational health regulatory bodies in UK, Switzerland and Germany, are awaiting scientific results before taking any actions, there are to some degree different approaches on how to deal with this complex problem. It seems the regulatory body in the UK is taking a more active role by initiating some review studies and preparing some guidelines for industry. The regulatory body in Germany has recently started to inform and involve themselves in the issue, whereas the regulatory body in Switzerland is more passive.

The NGO has taken on the role as an early whistle blower, provoking debate around the regulatory issue. It is also an important actor in contextualizing the debate for the media impacting the public opinion on NPM issues. It seems important to recognize the function of the NGO and utilize their positive attributes to influence a safe and responsible development of NPM.

Mindful the amounts of chemicals that are untested but market available, it is reasonable to 
Table 2. Summary of occupational health authorities' perception

\begin{tabular}{|c|c|c|}
\hline Uncertainties & Research Focus & Action \\
\hline What will the exposure be? & Kinetics of the particle/material. & $\begin{array}{l}\text { Wait until it is known which type } \\
\text { of substance will be used in } \\
\text { nanotechnologies and then do a } \\
\text { risk assessment. }\end{array}$ \\
\hline Which substances will be used? & Elaboration of the lung response. & Case by case examination. \\
\hline What is the dose-response? & Dermal exposure route. & Harmonize the test methods. \\
\hline $\begin{array}{l}\text { How will NPM contribute to the body } \\
\text { burden? }\end{array}$ & Effects on secondary organs. & $\begin{array}{l}\text { Contained usage of NPM when } \\
\text { appropriate. }\end{array}$ \\
\hline $\begin{array}{l}\text { Will the novel characteristics of the new } \\
\text { NPM also be an issue for toxicology? }\end{array}$ & Epistemiological studies on humans. & \\
\hline $\begin{array}{l}\text { NPM may have the same toxicity as bulk, } \\
\text { but will it impact the body in a } \\
\text { different way? }\end{array}$ & Toxic properties of the particle/material. & \\
\hline $\begin{array}{l}\text { What should be measured? (Mass/surface } \\
\text { area/volume) }\end{array}$ & Exposure data and methods & \\
\hline Will each NPM have its own characteristic? & $\begin{array}{l}\text { All particles with novel, catalytic } \\
\text { or binding properties (more } \\
\text { concerning) }\end{array}$ & \\
\hline
\end{tabular}

believe that it will also take many years before there is a sufficient knowledge base for the regulatory bodies to perform the traditional risk assessments of NPM and implement risk management actions. As seen from Table 3, both industry and regulatory bodies are concurrent in their views that regulations should only be initiated after the scientific knowledge base indicates clearly that NPM are hazardous. Furthermore, all stakeholders seem to want a case-by-case evaluation of the NPM. However, the researchers do not yet understand the fundamentals behind the properties of NPM. As such, achieving a sufficient level of knowledge demands much more research which we believe will take several years.

We also found in our research what appears to be some confusion about the terminology regarding NPM. The different stakeholder groups interviewed used different terms such as chemicals, ultrafine particles, nanoparticles, and nanomaterials. Therefore, a future task may be to develop a common terminology for all stakeholders, which would be especially important for discussing regulatory policy issues.

\section{Implications for regulatory policy}

In environmental settings, the gap of time between cause and effects is often much greater than the gap between human exposure and impacts. This makes it more difficult to provide the sufficient amount of scientific evidence that regulatory bodies normally demands. Industry, as illustrated in Table 1, believes that regulations should be imposed only when sufficient scientific evidence exists that justifies the need. The voluntary measures taken by industry themselves are seen by the industry as a sufficient level of precautionary measures. Whether the industry acknowledges the responsibility beyond protecting their workers against occupational risks to other stages of the life cycle of their products remains unknown. With the speed of technological development and the widespread foreseen market launching of NPM-based products, it may be insufficient and unrealistic to leave precautionary measures only to the industry.

How much research is undertaken by industry is difficult to estimate as the results remain normally unpublished and hidden from the public sphere. This practice was confirmed by an industrial representative in one of the interviews, blaming this on competitive reasons. The authors are only aware of a limited number of initiatives in Europe where the industry is partnering and the public can get insight into the results, such as the EU funded project NanoSafe2 (Nanosafe, 2006). The limited contributions from industry to the publicly available knowledge base would mean that it is public research money that has to finance this fundamental research. Whether it is legitimate to have public money finance and prove whether industrial products are safe seems an important question to 
Table 3. Overview and comparison of the stakeholders' perception

\begin{tabular}{|c|c|c|c|c|c|c|}
\hline Regulatory Issue & & Industry & $\mathrm{EC}$ & $\begin{array}{l}\text { Occupational } \\
\text { Health } \\
\text { Authorities }\end{array}$ & NGO & Scientists \\
\hline Need for Regulations & $\begin{array}{l}\text { Yes } \\
\text { No }\end{array}$ & $\mathrm{x}$ & $\mathrm{x}$ & $\mathrm{x}$ & $\mathrm{x}$ & $\mathrm{x}$ \\
\hline Type of Regulations & $\begin{array}{l}\text { Top-Down - Command and Control } \\
\text { Industrial Voluntary Initatives } \\
\text { and Self Regulations }\end{array}$ & $\mathrm{x}$ & $\begin{array}{l}? \\
?\end{array}$ & $\mathrm{x}$ & $\mathrm{x}$ & $\mathrm{x}$ \\
\hline Point of time & $\begin{array}{l}\text { Evidence Oriented } \\
\text { Proactive }\end{array}$ & $\mathrm{x}$ & $\mathrm{x}$ & $\mathrm{x}$ & $\mathrm{x}$ & $\mathrm{x}$ \\
\hline Covered issues & $\begin{array}{l}\text { NPM Case-by-case } \\
\text { All NPM }\end{array}$ & $\mathrm{x}$ & $\mathrm{x}$ & $\mathrm{x}$ & $\mathrm{x}$ & $\mathrm{x}$ \\
\hline
\end{tabular}

pose. Also, it could be argued that private stakeholders should provide resources for establishing the scientific evidence necessary that enables them to reap future profits in the market. The practice of industry to refuse to share results of some of their research may need to be challenged by regulatory bodies as transparency in technological development is fundamental for public trust and acceptance. The introduction of a disclosure practice would without much doubt both boost the scientific knowledge base and give all stakeholders a better chance for a sound evaluation of whether NPM pose risks to human health and the environment. In the long term, industry may profit from it in terms of the potential for increased consumer confidence in their products. To make this happen, changes related to risk assessment practices and decision making processes may need to take place both within regulatory bodies as well as industry. By demanding industry demonstrate their products are safe throughout the lifecycle, consumers may have greater confidence in the safety of these products for human health and the environment. Therefore, it may be time for applying the precautionary principle as a tool for boosting the scientific knowledge base and increase transparency.

At the moment, there are few initiatives in relation to regulatory policy in Europe. There are, however, some international initiatives. For example the International Council of Nanotechnology (ICON) has recently launched a research project that will investigate and recommend best practices for nanomaterials in industry (ICON, 2005). Establishing industry voluntary initiatives and self-regulations are important first steps to improve the practices in industry. The challenge is for the industry to follow up and continuously improve these practices once they are established and from a regulatory perspective to ensure that these voluntary initiatives are sufficient to safeguard the human health and environment. Another initiative is the global initiative of risk governance for nanotechnology under development by the Geneva based organisation IRGC, where stakeholder participation is one of the central elements (IRGC, 2004).

\section{Closing remarks}

Perceptions of regulations differ among the stakeholders. Although everybody seem to agree that some sort of regulations should be in place, there is disagreement on what type of regulations that should be. The scientific uncertainty regarding the risks of NPM makes the regulatory issue complex and ambiguous. To decrease the scientific uncertainty, more resources need to be committed to scientific research on the risk potential of NPM. However, the industry seems uncommitted to provide resources for this research, thus the burden may be on regulators to demonstrate whether NPM are safe or could potentially be dangerous. The assumption that tax-payers money should be allocated for this type of research may be unjustified as it is still greatly unknown how these industrial products will benefit the public. Therefore, industry should contribute to the scientific knowledge base. Consequently, we recommend regulations that ensure these contributions. 


\section{Acknowledgements}

The authors would like to thank Professor David Berube from the University of South Carolina for his editorial support.

\section{References}

Borm P.J., 2004. In: Helland A. (ed.) Nanoparticles: A Closer Look to the Risks to Human Health and the Environment. Perceptions and Precautionary Measures of Industry and Regulatory Bodies in Europe. Vol. IIIEE Reports 2004:05. Lund University, Lund: IIIEE, pp. 21-23.

Borm P.J. \& W. Kreyling, 2004. Toxicological hazards of inhaled nanoparticles - potential implications for drug delivery. J. Nanosci. Nanotechnol. 4(5), 521-531.

Bourne L. \& D. Walker, 2005. Visualising and mapping stakeholder influence. Manage. Decis. 43(5), 649-660.

Donaldson K., 2004a. The Toxicology of Airborne Nanoparticles. In: Health and Safety Laboratory, Nanomaterials: A Risk to Health at Work? Derbyshire, UK.

Donaldson K., 2004b. In: Helland A. (ed.) Nanoparticles: A Closer Look to the Risks to Human Health and the Environment. Perceptions and Precautionary Measures of Industry and Regulatory Bodies in Europe. Vol. IIIEE Reports 2004:05. Lund University, Lund: IIIEE, p. 22.

Donaldson K., D. Brown, A. Clouter, R. Duffin, W. MacNee, L. Renwick, L. Tran \& V. Stone, 2002. The pulmonary toxicology of ultrafine particles. J. Aerosol. Med. 15(2), 213-220.

EC, 2000. Communication from the commission on the precautionary principle. Brussels: European Commission.

EC, 2003. Proposal for a regulation of the European parliament and of the council concerning the registration, evaluation, authorisation and restriction of chemicals (reach), establishing a european chemicals agency and amending directive 1999/45/ec and regulation (ec) \{on persistent organic pollutants\}. Brussels: European Commission.

EC, 2004. Communication from the commission: Towards a European strategy for nanotechnology. Brussels: European Commission.

EC, 2005a. Communication from the commission: Nanosciences and nanotechnologies: An action plan for Europe 20052009. Brussels: European Commission.

EC, 2005b. REACH: Commission welcomes council's agreement on new EU chemical legislation. Retrieved February 13, 2006, from http://www.europa.eu.int/rapid/pressReleases Action.do? reference $=$ IP $/ 05 / 1583 \&$ format $=$ HTML\&aged $=$ $0 \&$ language $=\mathrm{EN} \&$ guiLanguage $=\mathrm{en}$.

Fortner J., D. Lyon, C. Sayes, A. Boyd, J. Falkner, E. Hotze, L. Alemanny, Y. Tao, W. Guo, K. Ausman, V.L. Colvin \& J. Hughes, 2005. C60 in water: Nanocrystal formation and microbial response. Environ. Sci. \& Technol. 39(11), 4307 4316.
Haum R., U. Petschow \& M. Steinfeldt, 2004. Nanotechnology and regulation within the framework of the precautionary principle. Berlin: Institut für ökologische Wirtschaftsforschung.

Helland A., 2004. Nanoparticles: A Closer Look at the Risks to Human Health and the Environment-Perceptions and Precautionary Measures of Industry and Regulatory Bodies in Europe. No. IIIEE Report: 2004:05. Lund University, Lund: IIIEE.

Hett A., 2004. Nanotechnology. Small matter, many unknowns (http://www.swissre.com/INTERNET/pwsfilpr.nsf/vwFileby IDKEYLu/ULUR-5YNGET/\$FILE/Publ04_Nanotech_en. pdf). Zurich: Swiss Reinsurance Company.

ICCA, 2005. Responsible care. Retrieved September 22, 2005, from http://www.responsiblecare.org/.

ICON, 2005. Review of best practices for nanomaterial safety: A request for proposals. Retrieved 31 January, 2006, from http://www.cohesion.rice.edu/centersandinst/icon/projects. cfm?doc_id $=4388$.

IRGC, 2004. Nanotechnology. Retrieved February 7, 2006, from http://www.irgc.org/.

Kreyling W., M. Semmler, F. Erbe, P. Mayer, S. Takenaka, H. Schulz, G. Oberdorster \& A. Ziesenis, 2002. Translocation of ultrafine insoluble iridium particles from lung epithelium to extrapulmonary organs is size dependent but very low. J. Toxicol. Environ. Health A 65(20), 1513-1530.

Lam C.-W., J.T. James, R. McCluskey \& R.L. Hunter, 2004. Pulmonary toxicity of single-wall carbon nanotubes in mice 7 and 90 days after intratracheal instillation. Toxicol. Sci. 77, 126-134.

Muller J., F. Huaux, N. Moreau, P. Misson, J.-F. Heilier, M. Delos, M. Arras, A. Fonseca, J. Nagy \& D. Lison, 2005. Respiratory toxicity of multi-wall carbon nanotubes. Toxicol. Appl. Pharm. 207(3), 221-231.

Nanosafe, 2006. Safe production and use of nanomaterials. Retrieved February 7, 2006, from http://www.nanosafe.org/ node/ 15 .

Nemmar A., H. Vanbilloen, M.F. Hoylaerts, P.H. Hoet, A. Verbruggen \& B. Nemery, 2001. Passage of intratracheally instilled ultrafine particles from the lung into the systemic circulation in hamster. Am. J. Respir. Crit. Care Med. 164(9), 1665-1668.

NSTC, 1999. Nanotechnology: Shaping the world atom by atom. Washington, DC: National Science and Technology Council.

Oberdorster E., 2004a. Manufactured nanomaterials (fullerenes, c60) induce oxidative stress in the brain of juvenile largemouth bass. Environ. Health Persp. 112(10), 10581062.

Oberdorster E., 2004b. In: Helland A. (ed.) Nanoparticles: A Closer Look to the Risks to Human Health and the Environment. Perceptions and Precautionary Measures of Industry and Regulatory Bodies in Europe. Vol. IIIEE Reports 2004:05. Lund University, Lund: IIIEE, p. 22.

Oberdorster G., 2001. Pulmonary effects of inhaled ultrafine particles. Int. Arch. Occup. Env. Hea. 74(1), 1-8.

Oberdorster G., E. Oberdorster \& J. Oberdorster, 2005. Nanotoxicology: An Emerging Discipline Evolving from 
Studies of Ultrafine Particles. National Institute of Environmental Health Sciences.

Oberdorster G., Z. Sharp, V. Atudorei, A. Elder, R. Gelein, W. Kreyling \& C. Cox, 2004. Translocation of inhaled ultrafine particles to the brain. Inhal. Toxicol. 16(6-7), 437-445.

Oberdorster G., Z. Sharp, V. Atudorei, A. Elder, R. Gelein, A. Lunts, W. Kreyling \& C. Cox, 2002. Extrapulmonary translocation of ultrafine carbon particles following wholebody inhalation exposure of rats. J. Toxicol. Environ. Health A 65(20), 1531-1543.

Roco M.C., 2005. The emergence and policy implications of converging new technologies integrated from the nanoscale. J. Nanoparticle Res. 7, 129-143.

Sayes C.M., F. Liang, J.L. Hudson, J. Mendez, W. Guo, J.M. Beach, V.C. Moore, C.D. Doyle, J.L. West, W.E. Billups, K.D. Ausman \& V.L. Colvin, 2006. Functionalization density dependence of single-walled carbon nanotubes cytotoxicity in vitro. Toxicol. Lett. 161(2), 135 .

Service R.F., 2004. Nanotechnology grows up. Science 304, $1732-1734$.

Shvedova A.A., E.R. Kisin, R. Mercer, A.R. Murray, V.J. Johnson, A.I. Potapovich, Y.Y. Tyurina, O. Gorelik, S. Arepalli, D. Schwegler-Berry, A.F. Hubbs, J. Antonini, D.E. Evans, K. Bon-Ki, D. Ramsey, A.D. Maynard, V.E. Kagan, V. Castranova \& P.A. Baron, 2005. Unusual inflammatory and fibrogenic pulmonary responses to single walled carbon nanotubes in mice. Am. J. Physiol. Lung Cell Mol. Physiol. June 10 (Epub ahead of print).

Stone V., 2004. In: Helland A. (ed.) Nanoparticles: A Closer Look to the Risks to Human Health and the Environment. Perceptions and Precautionary Measures of Industry and
Regulatory Bodies in Europe. Vol. IIIEE Reports 2004:05. Lund University, Lund: IIIEE, pp. 21-23.

Takenaka S., E. Karg, W. Kreyling, B. Lentner, H. Schulz, A. Ziesenis, P. Schramel \& J. Heyder, 2004. Fate and toxic effects of inhaled ultrafine cadmium oxide particles in the rat lung. Inhal. Toxicol. 16 (Suppl. 1), 83-92.

Takenaka S., E. Karg, C. Roth, H. Schulz, A. Ziesenis, U. Heinzmann, P. Schramel \& J. Heyder, 2001. Pulmonary and systemic distribution of inhaled ultrafine silver particles in rats. Environ. Health Perspect. 109 (Suppl. 4), 547-551.

The Royal Society \& The Royal Academy of Engineering, 2004. Nanoscience and nanotechnologies: Opportunities and uncertainties (http://www.nanotec.org.uk/finalReport.htm): The Royal Society \& The Royal Academy of Engineering.

von Klot S., A. Peters, P. Aalto, T. Bellander, N. Berglind, D. D'Ippoliti, R. Elosua, A. Hormann, M. Kulmala, T. Lanki, H. Lowel, J. Pekkanen, S. Picciotto, J. Sunyer, F. Forastiere; Health Effects of Particles on Susceptible Subpopulations Study Group, 2005. Ambient air pollution is associated with increased risk of hospital cardiac readmissions of myocardial infarction survivors in five european cities. Circulation 112(20), 3073-3079.

Warheit D.B., 2004. Nanoparticles: Health impacts?. Materials Today 7(2), 32-35.

Warheit D.B., B.R. Laurence, K.L. Reed, D.H. Roach, G.A. Reynolds \& T.R. Webb, 2004. Comparative pulmonary toxicity assessment of single-wall carbon nanotubes in rats. Toxicol Sci 77(1), 117-125.

Zhang Q., Y. Kusaka, X. Zhu, K. Sato, Y. Mo, T. Kluz \& K. Donaldson, 2003. Comparative toxicity of standard nickel and ultrafine nickel in lung after intratracheal instillation. J. Occup. Health 45(1), 23-30. 